\title{
Valva ou Válvula?
}

\author{
Aloir Queiroz de Araujo
}

Vitória, ES

“...você é portador de valva aórtica bicúspide. Em vez de conter três válvulas a sua valva só contém duas válvulas..."

Verifica-se, na literatura cardiológica brasileira dos últimos anos, um nítido predomínio da utilização do termo valva, assim como palavras derivadas (valvopatia, valvoplastia, valvar, etc), em detrimento de válvula, para se designar as quatro estruturas cardíacas e tudo que se refere às mesmas. Nos dois últimos anos, nos Arquivos Brasileiros de Cardiologia, constata-se a presença de valva em 16 títulos de artigos publicados, enquanto que válvula simplesmente não aparece. Numa busca eletrônica, no mesmo periódico, de 1996 a 2001, valva aparece 157 vezes, para 48 utilizações de válvula. Lendo-se o Programa Final do $18^{\circ} \mathrm{Con}-$ gresso de Cardiologia da Sociedade de Cardiologia do Estado do Rio de Janeiro (julho de 2001), encontra-se que a SOCERJ possui o seu Departamento de Valvulopatias, mas na programação científica poucas apresentações são "valvulares". No Dicionário do Coração, disponível na página da SBC na internet (www.cardiol.br), verifica-se que o coração possui quatro válvulas (com seus respectivos nomes) as quais são constituídas por valvas.

Devemos conviver com as duas terminologias? Não parece adequado pois são estruturas que sofrem uma grande variedade de processos patológicos, presentes no cotidiano do cardiologista, e é desejável uma uniformização da linguagem. A seguir, serão apresentados argumentos que fortalecem a minoria "valvular".

Em dicionários da língua portuguesa ${ }^{1}$, valva é estrutura botânica e zoológica (conchas), não constando como substantivo anatômico humano. Já o substantivo válvula, além de significar pequena valva, é usado para estruturas biológicas e mecânicas, indicando, em medicina, pregas

Hospital das Clínicas da Universidade Federal do Espírito Santo Correspondência: Aloir Queiroz de Araujo - Rua Alfeu Alves Pereira, 60 - 29050-190 Vitória, ES - E-mail: aloirqueiroz@cardiol.br

Recebido para publicação em 19/11/01

Aceito em 29/11/01 membranosas que existem no coração e em certos vasos sangüíneos para obstar ao refluxo do sangue.

$\mathrm{Na}$ língua inglesa, o substantivo valve ${ }^{2}$ é utilizado para as estruturas mecânicas, anatômicas, zoológicas e botânicas referidas acima. Entretanto, em publicações médicas que se referem ao coração há o adjetivo valvular (valvular heart disease, valvular stenosis). Pesquisando-se na MEDLINE (National Library of Medicine-USA), há 2.195 ocorrências de valvuloplasty para apenas 117 de valvoplasty. Nestas, a grande maioria é de artigos de fora dos Estados Unidos, incluindo algumas importantes publicações de brasileiros que podem não estar sendo citadas em outros trabalhos devido a uma indexação inadequada. Em outra busca, no conceituado The New England Journal of Medicine, desde 1975, valvoplasty nunca foi citado, enquanto valvuloplasty aparece em 41 oportunidades.

Em Portugal, como pode ser verificado na Revista Portuguesa de Cardiologia, os colegas lusitanos usam regularmente os termos válvula, valvular e valvulopatia.

Em países cujos idiomas, como o nosso, carregam influência do latim, também não há dupla terminologia. A saber:

França - Archives de Maladies du Coeur et des Vaisseaux: valve-valvulaire-valvulopathies.

Itália - Giornale Italiano di Cardiologia: valvolavalvolare-valvolopaties.

Espanha-Revista Española de Cardiología: válvulavalvular-valvulopatías.

É na interpretação do latim ${ }^{3}$ que se origina a duplicidade, em que valva significa, tanto as estruturas botânicas e zoológicas, quanto as cardiovasculares, e valvula é o seu diminutivo. A terminologia anatômica atual é sistematizada pela Federação Internacional das Associações de Anatomistas, que se reuniu pela última vez na cidade de São Paulo, em agosto de 1997. A FIAA publica a Nomina Anatomica (nomenclatura anatômica), onde todas as estruturas macroscópicas do corpo humano são denominadas em latim e inglês ${ }^{4}$, sendo posteriormente traduzida para os diversos idiomas, de acordo com cada associação nacional. A própria Nomina não resistiu ao ímpeto reformista e passou a ser chamada de terminologia anatômica. Ficou estabelecido que o termo latino valva deve ser restrito às quatro estruturas cardíacas, enquanto que valvula denomina as demais 
estruturas vasculares e viscerais e também os componentes da valva. Assim, de acordo com a convenção dos anatomistas, em latim, a valva possui valvulas. Num passado próximo, a tradução para o português ${ }^{5}$ recomendava o contrário.

Recentemente, a Sociedade Brasileira de Anatomia lançou a edição atualizada da terminologia anatômica ${ }^{6}$. Obra louvável pelo cuidado descritivo sistemático, faz uma verdadeira dissecção humana. Contudo, caso venha a ser oficialmente adotada por cardiologistas, deixará muita gente com nostalgia. A mitral, por exemplo, nãoé mais citada, substituída que foi por valva atrioventricular esquerda, entre outras alterações difíceis de serem assimiladas na prática.

Está bem estabelecido em nossas comunidades, científica e leiga, que qualquer estrutura que permite a passagem de um fluido num sentido e impede o seu retorno é uma válvula, seja num motor, numa câmara de ar, ou no coração. A tricúspide, quando lesada, tem prejudicada a sua função valvular gerando uma doença que deve ser descrita como valvulopatia. Para aqueles que defendem uma linguagem médica diretamente ligada à Nomina Anatomica, há um ponto importante a ser frisado: os termos ali presentes são anatômicos, sem referência ao patológico. Não é adequado chamar uma prótese de valva pois é uma estrutura estranha à anatomia e irá desempenhar função valvular após seu implante, da mesma forma que um tubo não é valvado e sim valvulado. Como denominar as válvulas únicas de determinadas cardiopatias congênitas? a doença reumática provoca valvulite ou valvite?

Inúmeros exemplos podem ser apresentados da inadequacidade dos neologismos advindos do uso do termo valva. Porém, há de se reconhecer que estão enraizados e a tendência dos neologismos aceitos pela maioria é de que sejam oficializados. E foi o que aconteceu. Naúltima edição do Aurélio ${ }^{7}$, todos os termos médicos que utilizam a estrutura -valvul- são considerados impróprios ou obsoletos. Resta saber se quem orientou os editores do famoso dicionário atentou para os pontos de vista histórico, físico, anatômico, fisiológico e patológico, que indicam ser o coração humano possuidor de quatro válvulas. Publicado em 2001, o excelente dicionário Houaiss ${ }^{8}$ é pragmático. Admite a orientação dos anatomistas mas preserva os tradicionais valvulotomia, valvuloplastia, etc.

Como a maioria dos cardiologistas demonstra preferência por valva, fica a sugestão para que a Sociedade Brasileira de Cardiologia, que tem gerado valiosas diretrizes científicas, crie uma comissão para sistematizar a terminologia cardiológica que tem estado um pouco confusa, principalmente pela chegada volumosa de novos termos estrangeiros, cujas traduções ou adaptações vão do correto ao inadequado, passando por expressões de gosto duvidoso.

\section{Referências}

Grande Dicionário Universal da Língua Portuguesa. Cacém: Texto Editora, 1997. Webster's Dictionary. Ohio: Landoll, 1993: 325.

Merrian Webster Medical Dictionary. Ohio: Merrian Webster Inc., 1997.

. Federative Committee on Anatomical Terminology: Terminologia Anatomica. Stutgart: Georg Verlag, 1998.

5. Comissão Luso-Brasileira de Nomenclatura Morfológica: Nomenclatura anatômica. Rio de Janeiro: G. Koogan, 1977: 79.
6. Sociedade Brasileira de Anatomia: Terminologia Anatômica. São Paulo: Manole, 2001.

7. Novo Aurélio Século XXI: O Dicionário da Língua Portuguesa, $3^{\mathrm{a}}$ ed. Rio de Janeiro: Nova Fronteira, 1999.

8. Antonio Houaiss, Mauro de Salles Villar: Dicionário Houaiss da Língua Portuguesa. Rio de Janeiro: Objetiva, 2001. 